Article

\title{
Ratiometric Fluorescent Nanoprobe for Highly Sensitive Determination of Mercury Ions
}

\author{
Zhihui Luo ${ }^{1,2,3}$, Hui Xu ${ }^{1,3}$, Baogui Ning ${ }^{2}$, ZeBin Guo ${ }^{1,3}{ }^{-1}, \mathrm{Na} \mathrm{Li}^{2}$, Lina Chen ${ }^{2}$, \\ Guobao Huang ${ }^{2}$, Charlie $\mathrm{Li}^{4, *}$ and Baodong Zheng ${ }^{1,3, * \mathbb{D}}$ \\ 1 College of Food Science, Fujian Agriculture and Forestry University, Fuzhou, Fujian 350002, China; \\ lzhui_1980@163.com (Z.L.); xhuifst@163.com (H.X.); gzb8607@163.com (Z.G.) \\ 2 Guangxi Key Laboratory of Agricultural Resources Chemistry and Biotechnology, College of Chemistry and \\ Food Science, Yulin Normal University, Yulin, Guangxi 537000, China; ningbg1108@163.com (B.N.); \\ ln19860622@126.com (N.L.); lnchen2018@163.com (L.C.); lzjx0915@163.com (G.H.) \\ 3 Engineering Research Center of Marine Living Resources Integrated Processing and Safety Risk Assessment, \\ Fuzhou, Fujian 350002, China \\ 4 Department of Environmental Toxicology, University of California-Davis, Davis, CA 95616, USA \\ * Correspondence: csjli@ucdavis.edu (C.L.); zbdfst@163.com (B.Z.); Tel.: +86-0591-83705076 (B.Z.)
}

Received: 24 April 2019; Accepted: 18 June 2019; Published: 19 June 2019

\begin{abstract}
In this study, a novel dual-emission ratiometric fluorescent nanoprobe (RFN) was synthesized and ultilized for highly sensitive determination of mercury ions. In this nanoprobe, fluorescein isothiocyanate (FITC) doped silica $\left(\mathrm{SiO}_{2}\right)$ served as a reference signal, $\mathrm{FITC}-\mathrm{SiO}_{2}$ microspheres were synthesized and modified with amino groups, and then $\mathrm{Au}$ Nanoclusters (AuNCs) were combined with the amino groups on the surface of the FITC- $\mathrm{SiO}_{2}$ microspheres to obtain the RFN. The selectivity, stability, and pH of the RFN were then optimized, and the determination of mercury ions was performed under optimal conditions. The probe fluorescence intensity ratio $\left(\mathrm{F}_{520} \mathrm{~nm} / \mathrm{F}_{680} \mathrm{~nm}\right)$ and $\mathrm{Hg}^{2+}$ concentration $\left(1.0 \times 10^{-10} \mathrm{~mol} / \mathrm{L}\right.$ to $\left.1.0 \times 10^{-8} \mathrm{~mol} / \mathrm{L}\right)$ showed a good linear relationship, with a correlation coefficient of $\mathrm{R}^{2}=0.98802$ and a detection limit of $1.0 \times 10^{-10} \mathrm{~mol} / \mathrm{L}$, respectively. The probe was used for the determination of trace mercury ion in water samples, and the recovery rate was $98.15 \sim 100.45 \%$, suggesting a wide range of applications in monitoring pollutants, such as heavy metal ion and in the area of environmental protection.
\end{abstract}

Keywords: ratiometric fluorescent nanoprobe; dual-emission; mercury ions; determination

\section{Introduction}

Mercury is commonly found in the environment and is one of the most toxic elements [1]. It cannot be degraded by microorganisms in water. Mercury and some of its salts are volatile, thus possessing high mobility, corrosivity, and carcinogenicity. It can cause cell division damage and permanent damage to the central nervous system through skin and respiratory system, and it is one of the most common environmental pollutants [2-4]. According to the United States Environmental Protection Agency, the maximum concentration of mercury ions in human daily drinking water should not exceed $10 \mathrm{nmol} / \mathrm{L}(\mathrm{ppb})$. Therefore, it is of great significance to establish a method with high sensitivity and selectivity for detecting mercury ions in the environment.

At present, the effective methods for determining mercury ions include atomic absorption spectroscopy, inductively coupled plasma mass spectrometry, inductively coupled plasma-atomic emission spectrometry, and so on [5-7]. However, to perform these with a high accuracy, these methods are time-consuming, expensive, and require professional operation. To overcome these shortcomings, the fluorescence (FL) method is often employed, as it has high sensitivity and selectivity, 
and is relatively easy to handle [8,9]. In recent years, the determination of mercury ions based on the establishment of fluorescence sensors has attracted much attention, including probes such as organic dyes [10,11], complexes [12], quantum dots [13], and peptides [14]. Compared with a single quencher, the dual-emission ratiometric fluorescent probe has the characteristics of large molar absorbance, good stability, strong anti-interference, and long emission wavelength, which proved to be an effective method for complex sample matrices, and it is the current direction for the research in mercury ion detection [15-17].

In this study, $\mathrm{FITC}-\mathrm{SiO}_{2}$ was synthesized, and modified with amino groups, and then AuNCs was combined with the amino compounds on the surface of $\mathrm{FITC}-\mathrm{SiO}_{2}$ microspheres to generate the RFN. By optimizing the interference, stability, and $\mathrm{pH}$ conditions of the RFN, The detection performance of the RFN on mercury ions was further explored and applied to the determination of water samples.

\section{Results and Discussion}

\subsection{Fluorescence Spectra of RFN}

Figure 1a shows the photographs of $\mathrm{FITC}-\mathrm{SiO}_{2}$ (I), RFN (II) and AuNCs (III) under white light, and Figure $1 \mathrm{~b}$ exhibits the corresponding photographs under ultraviolet light. As shown in these figures, the nanoparticles in various synthetic stages all exhibited excellent optical properties. The solutions of AuNCs and FITC-SiO 2 showed red and green emissions, respectively, while the synthesized RFN (II) exhibited the complexed orange color. When the fluorescence spectra were subsequently measured by excitation wavelength of $380 \mathrm{~nm}$, the maximum emission wavelengths of AuNCs and FITC-SiO ${ }_{2}$ were $698 \mathrm{~nm}$ and $520 \mathrm{~nm}$, and the dual-emission peaks of the RFN were $520 \mathrm{~nm}$ and $680 \mathrm{~nm}$, respectively. This indicated that the fluorescence wavelength of the AuNCs coupled to the FITC- $\mathrm{SiO}_{2}$ microspheres had undergone a blue shift, which might be due to the fact that the binding of amino compounds on the surface changed as a result of the activation effect of EDC.

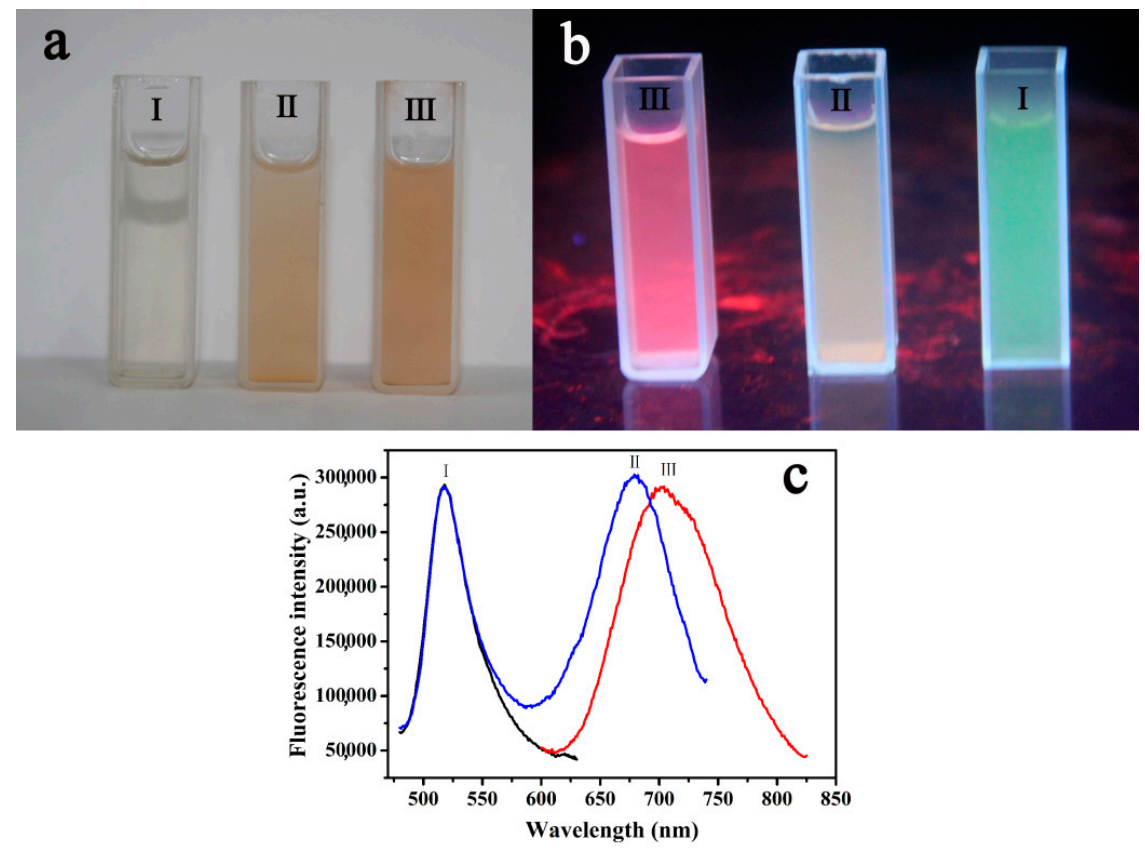

Figure 1. Photographs of the FITC-SiO 2 (I), RFN (II), and AuNCs (III) in the sunlight (a) and under the ultraviolet lamp (b). The FL spectra of FITC-SiO 2 (I), RFN (II), and AuNCs (III) (c).

\subsection{Transmission Electron Microscopy (TEM) of RFN}

To prove that AuNCs were successfully attached to the surface of $\mathrm{FITC}-\mathrm{SiO}_{2}$ nanoparticles, the synthesized ratiometric fluorescent nanomaterials were characterized by TEM (Figure 2). Figure 2a 
shows the electron micrograph of $\mathrm{SiO}_{2}-\mathrm{FITC}$, and Figure $2 \mathrm{~b}$ shows the electron micrograph of RFN. As seen in the figures, the prepared $\mathrm{FITC}-\mathrm{SiO}_{2}$ nanoparticles had a dimension of about $100 \mathrm{~nm}$, while the particle size of RFN are $120 \mathrm{~nm}$. It shows that the RFN had a very good dispersity. According to the literature [18,19], the particle size of the Au NCs was only about $1-2 \mathrm{~nm}$, it was difficult to observe the AuNCs on the outer layer of $\mathrm{FITC}-\mathrm{SiO}_{2}$ (Figure 2c) due to the aggregation of silica layer during the linking of AuNCs.

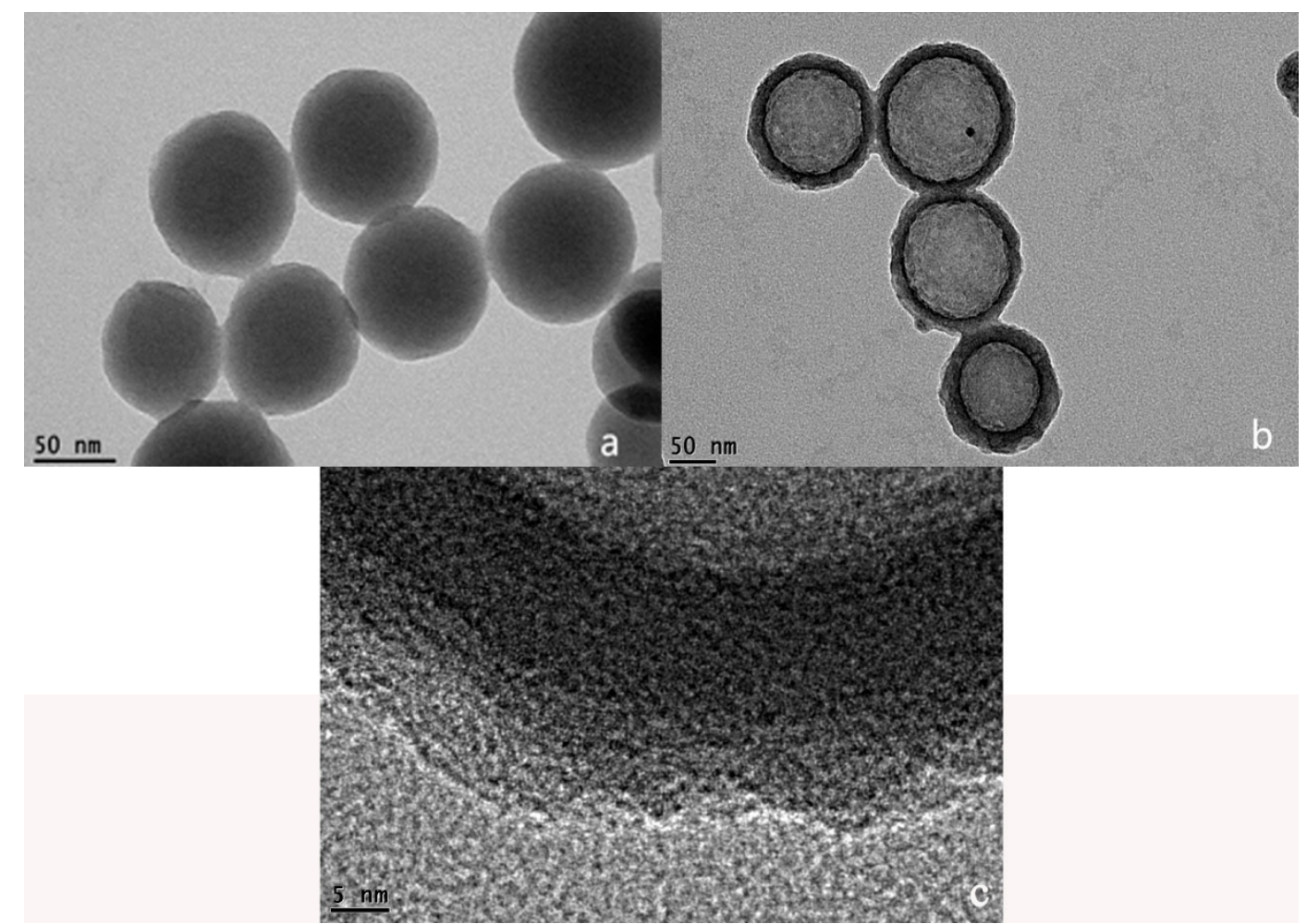

Figure 2. TEM of FITC-SiO 2 (a), RFN (b), and high resolution transmission electron microscopy (HRTEM) image of the outer surface of the RFN (c).

\subsection{Energy Dispersive X-Ray Spectroscopy (EDS) of RFN}

To further prove the AuNCs were successfully coupled with $\mathrm{FITC}-\mathrm{SiO}_{2}$, the synthesized material was analyzed by electron scattering spectroscopy. Figure S1 shows the elements including oxygen, silicon, and gold on the RFN, confirming the AuNCs have been successfully link to the suface of FITC-SiO ${ }_{2}$.

\subsection{Fluorescence Stability of RFN}

To demonstrate the stability of the RFN, $150 \mu \mathrm{L}$ of RFN and $500 \mu \mathrm{L}$ of $2.5 \times 10^{-9} \mathrm{moL} / \mathrm{L} \mathrm{Hg}^{2+}$ were placed in a $4 \mathrm{~mL}$ cuvette, and $3.35 \mathrm{~mL}$ of water was added to adjust the volume. Under the same conditions, one group was measured every three minutes, and ten other groups were measured in parallel. As shown in Figure 3, the fluorescence intensity of the RFN varied only slightly at 520 or $680 \mathrm{~nm}$, demonstrating the good stability of the RFN. 


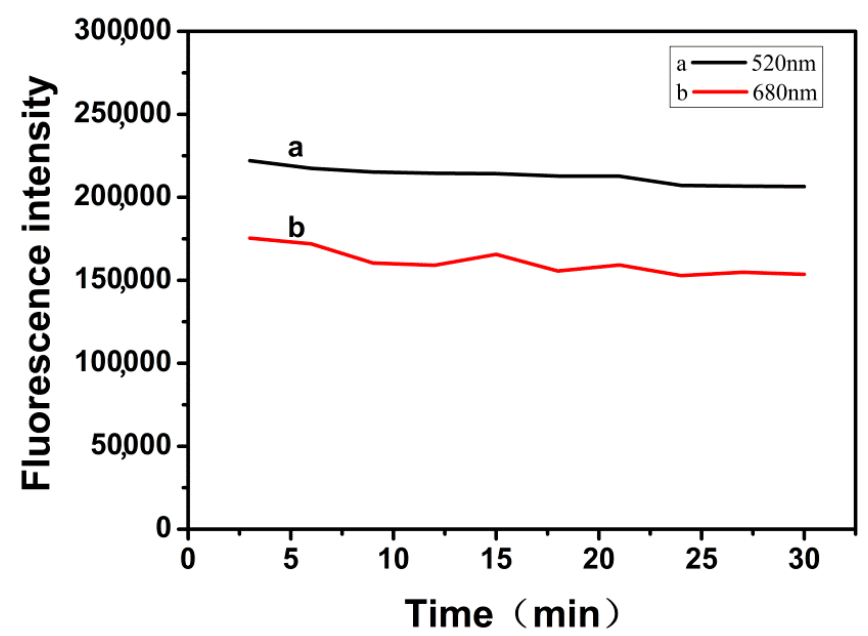

Figure 3. The fluorescence intensity of the RFN under $30 \mathrm{~min}$.

\subsection{Effect of Buffer Solutions at Different $p H$ Value on the RFN}

To study the effect of $\mathrm{pH}$ on the recognition of metal ions by RFN, we investigated the effect of buffer solutions at different $\mathrm{pH}$ values on the maximum fluorescence emission intensity of the RFN in the $\mathrm{pH}$ range of 6-11, with and without $\mathrm{Hg}^{2+}$. We selected the Britton-Robinson buffer system as the buffer solution and prepared various buffer solutions with different $\mathrm{pH}$ values in advance. The experiment was divided into two groups. For the first group, $100 \mu \mathrm{L}$ of RFN was added directly to $3.4 \mathrm{~mL}$ of buffer solution at various $\mathrm{pH}$ values, and then $500 \mu \mathrm{L}$ of $2.5 \times 10^{-9} \mathrm{~mol} / \mathrm{L} \mathrm{Hg}^{2+}$ solution was added; for the other group, $100 \mu \mathrm{L}$ of RFN was directly added to $3.4 \mathrm{~mL}$ of buffer solutions at various $\mathrm{pH}$ values without the addition of $\mathrm{Hg}^{2+}$ solution. The results are shown in Figure 4. The black square points represented the fluorescence intensity ratio of $\mathrm{F}_{520 \mathrm{~nm}} / \mathrm{F}_{680 \mathrm{~nm}}$ in the solutions of RFN with different $\mathrm{pH}$ values without the addition of $\mathrm{Hg}^{2+}$ solution, and the red dot represented the fluorescence intensity ratio of $\mathrm{F}_{520 \mathrm{~nm}} / \mathrm{F}_{680 \mathrm{~nm}}$ of the RFN after the addition of $\mathrm{Hg}^{2+}$ solutions. It can be seen from the figure that when $\mathrm{Hg}^{2+}$ was not added, the fluorescence intensity ratio decreased at $\mathrm{pH}=$ 6.37-7.24 and fluctuated slightly between $\mathrm{pH}=7.24-10.38$, having the highest intensity ratio and the best quenching effect at $\mathrm{pH}=6.37$. When $\mathrm{Hg}^{2+}$ was added, the fluorescence intensity ratio decreased between $\mathrm{pH}=6.37-7.24$ and $\mathrm{pH}=9.15-10.38$, increased with fluctuations between $\mathrm{pH}=7.24-9.15$, and the highest intensity was at $\mathrm{pH}=9.15$ with the best quenching effect.

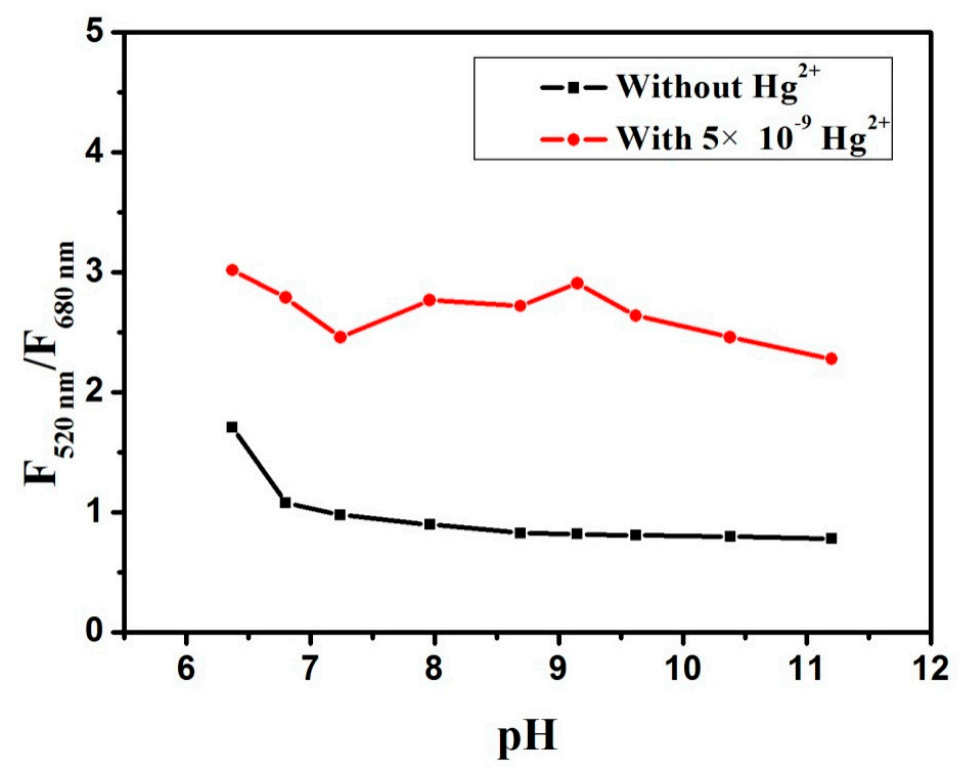

Figure 4. The $\mathrm{F}_{520 \mathrm{~nm}} / \mathrm{F}_{680 \mathrm{~nm}}$ intensity of RFN under the different of $\mathrm{pH}$. 


\subsection{Selectivity of the RFN to $\mathrm{Hg}^{2+}$}

To demonstrate the selectivity of the RFN for the detection of mercury ions, $100 \mu \mathrm{L}$ of the RFN was added to a $4 \mathrm{~mL}$ cuvette, followed by the addition of $500 \mu \mathrm{L}$ of different types of common metal ions and amino acids, which were detected at room temperature for $5 \mathrm{~min}$. As shown in Figure 5, among the interfering substance tested including $\mathrm{K}^{+}, \mathrm{Na}^{+}, \mathrm{Cd}^{2+}, \mathrm{Cr}^{3+}, \mathrm{Zn}^{2+}, \mathrm{Pb}^{2+}, \mathrm{Ti}^{3+}, \mathrm{Sn}^{2+}, \mathrm{Fe}^{3+}, \mathrm{Cu}^{2+}, \mathrm{Ag}^{+}$, $\mathrm{Fe}^{2+}, \mathrm{Glu}, \mathrm{Gly}$, L-As, $\mathrm{L}-\mathrm{Gl}$, only $\mathrm{Hg}^{2+}$ caused a significant decrease in fluorescence intensity, while other metal ions had almost no effect on the fluorescence spectra of the RFN. The dual-emission fluorescence ratio $\left(\mathrm{F}_{520 \mathrm{~nm}} / \mathrm{F}_{680 \mathrm{~nm}}\right)$ was around 1 , and only when $\mathrm{Hg}^{2+}$ was added, the $\mathrm{F}_{520 \mathrm{~nm}} / \mathrm{F}_{680 \mathrm{~nm}}$ reached 7.71 . Under the same conditions, even if the concentration of other ions was much higher than that of $\mathrm{Hg}^{2+}$, the RFN could not be interfered, which could be used for selectively identify $\mathrm{Hg}^{2+}$ with low concentrations, resulting in quenching of the red fluorescence. That is, $\mathrm{Hg}^{2+}$ could quench the second peak of the fluorescence spectrum of the fluorescent probe, while other ions had no obvious quenching effect. This result indicated that the RFN has good selectivity and specificity.

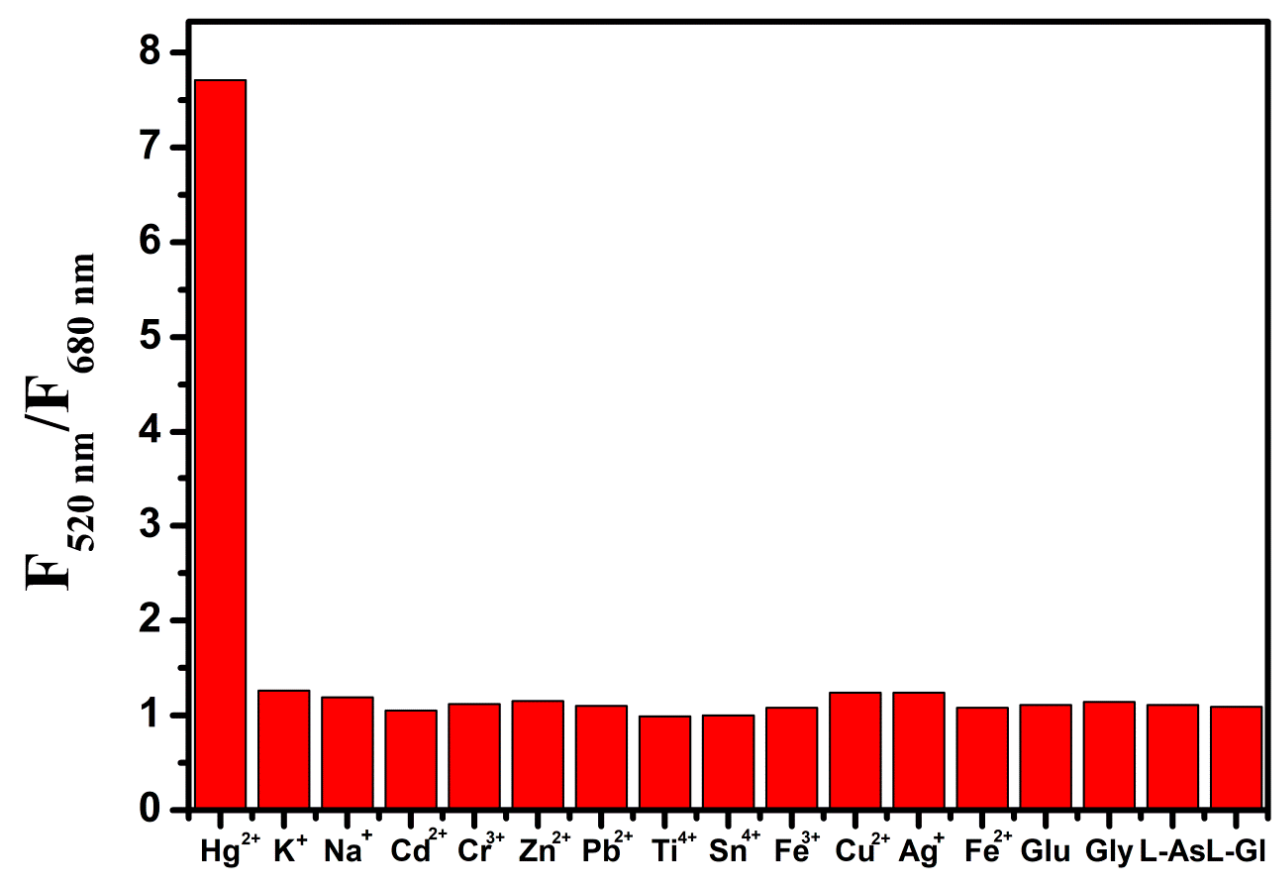

Figure 5. The $\mathrm{F}_{520 \mathrm{~nm}} / \mathrm{F}_{680 \mathrm{~nm}}$ intensity of RFN to various metal ions and amino acids $(1.0 \mathrm{mM})$.

\subsection{Determination of Mercury Ions}

To test the feasibility of the RFN for detecting $\mathrm{Hg}^{2+}$, different concentrations of $\mathrm{Hg}^{2+}$ were added to the RFN and the change in fluorescence intensity was examined. Figure 6 is the change in fluorescence spectrum of $100 \mu \mathrm{L}$ ratio fluorescent probe and $3.4 \mathrm{~mL}$ high purity water with the addition of $500 \mu \mathrm{L}$ of variously concentrated $\mathrm{Hg}^{2+}$ solution. The double emission peaks of RFN were at $520 \mathrm{~nm}$ and $680 \mathrm{~nm}$, respectively, and the maximum emission wavelength was $680 \mathrm{~nm}$. With the increase of $\mathrm{Hg}^{2+}$ concentration, the fluorescence intensity of the second peak of RFN gradually weakened. The fluorescence intensity was completely quenched when the $\mathrm{Hg}^{2+}$ concentration reached $1 \times 10^{-8} \mathrm{~mol} / \mathrm{L}$. The fluorescence intensity was highly sensitive at $680 \mathrm{~nm} \mathrm{Hg}^{2+}$, and decreased with the increase of $\mathrm{Hg}^{2+}$ concentration. The mechanism of fluorescence quenching caused the metallophilic $\mathrm{Hg}^{2+}-\mathrm{Au}^{+}$interactions in our experiment, because the surface of AuNCs with a small amount of $\mathrm{Au}^{+}$ should have strong and specific interactions with $\mathrm{Hg}^{2+}$, which leads to a serious quenching of the AuNCs fluorescence [19]. Moreover, there was no significant change in the peak at $520 \mathrm{~nm}$ throughout the experiment, indicating that the $520 \mathrm{~nm}$ emission peak could be used as an internal reference. 


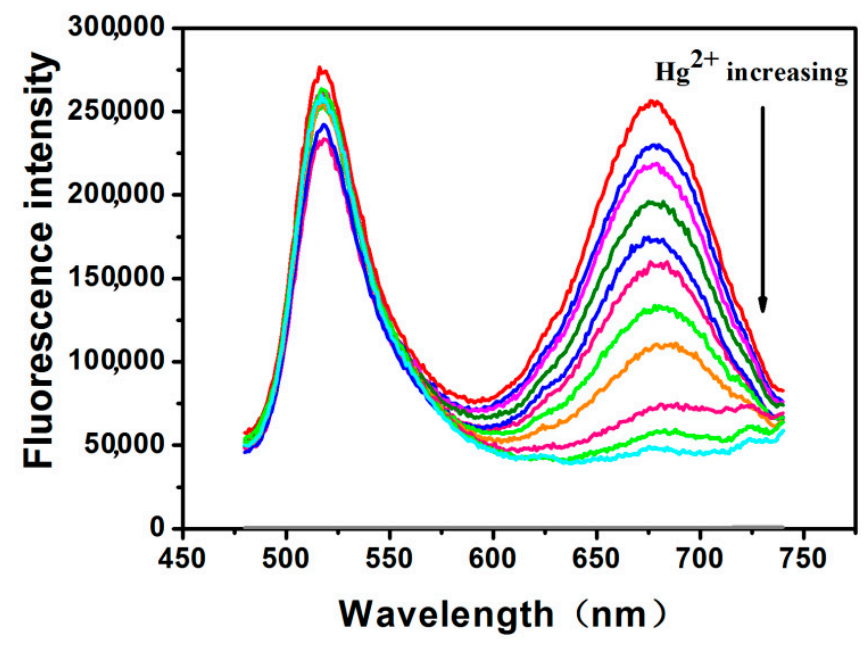

Figure 6. The FL spectra of RFN under different mercury concentrations $\left(1 \times 10^{-10}, 2.5 \times 10^{-10}\right.$, $\left.5 \times 10^{-10}, 7.5 \times 10^{-10}, 1 \times 10^{-9}, 2 \times 10^{-9}, 2.5 \times 10^{-9}, 3.5 \times 10^{-9}, 5 \times 10^{-9}, 7.5 \times 10^{-9}, 1 \times 10^{-8} \mathrm{~mol} / \mathrm{L}\right)$ $\left(\lambda_{\mathrm{ex}}=380 \mathrm{~nm}\right)$.

Figure 7 suggested that the $\mathrm{Hg}^{2+}$ exhibited a good linear relationship within the concentration range of $1.0 \times 10^{-10} \mathrm{~mol} / \mathrm{L}$ to $1.8 \times 10^{-8} \mathrm{~mol} / \mathrm{L}$. The linear correlation coefficient was $\mathrm{R}^{2}=0.98802$, the linear regression equation was $Y=1.11368+0.04431 \mathrm{X}$, and the detection limit was $1.0 \times 10^{-10} \mathrm{~mol} / \mathrm{L}$. The quantitative analysis of $\mathrm{Hg}^{2+}$ concentration in samples based on this linear relationship indicated that this probe had a good application prospect in detecting $\mathrm{Hg}^{2+}$ in water samples.

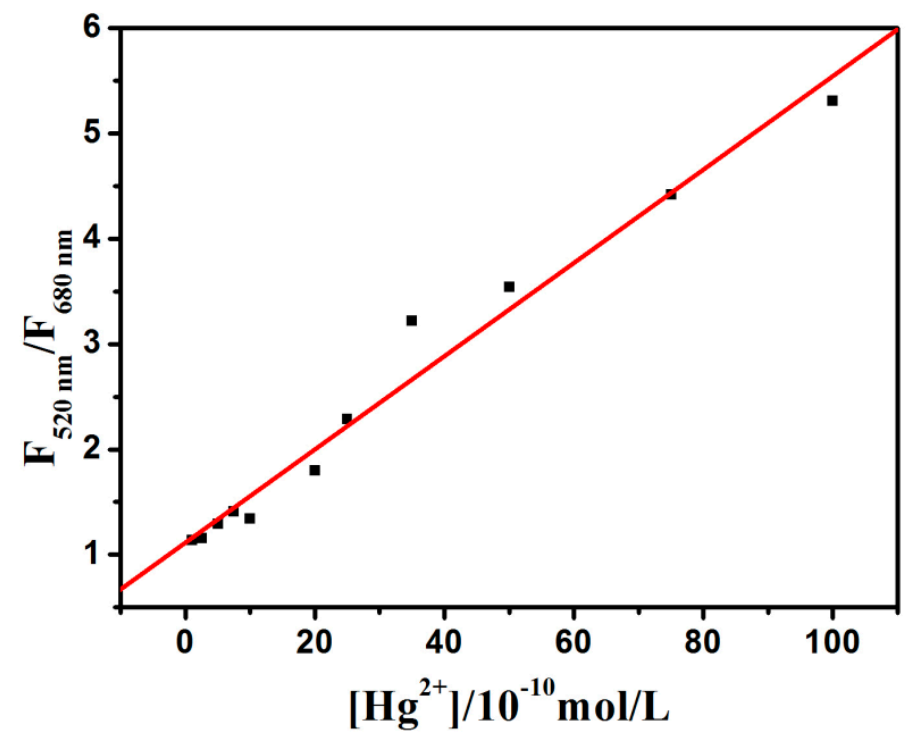

Figure 7. The $\mathrm{F}_{520 \mathrm{~nm}} / \mathrm{F}_{680 \mathrm{~nm}}$ intensity of RFN versus the concentration of $\mathrm{Hg}^{2+}$.

\subsection{Detection of Water Samples}

Based on the superior electivity and sensitivity of the RFN in the buffer solutions, we further applied it to the detection of actual water samples. The water samples in this experiment were taken from Tiannan Lake and the tap water. Before the experiment, the water sample was centrifuged and its supernatant was taken for the experiment. A $500 \mu \mathrm{L}$ of Tiannan Lake water sample or tap water sample were mixed with $500 \mu \mathrm{L}$ of a certain concentration of mercury ion solution, and then mixed with a $150 \mu \mathrm{L}$ of the RFN to make the total volume of $4 \mathrm{~mL}$. As shown in Table 1, the standard recovery rate of mercury ions were detected at room temperature, and the recovery was calculated to be between $98.15 \%$ and $100.45 \%$ by linear regression equation, indicating that the method had good accuracy. 
Table 1. The RFN for the detection of $\mathrm{Hg}^{2+}$ in Tiannan lake water and tap water.

\begin{tabular}{ccccc}
\hline \multirow{2}{*}{ Sample } & \multicolumn{4}{c}{$\mathbf{H g}^{\mathbf{2}}$ Concentration } \\
\cline { 2 - 5 } & Present Method & Added & Total & Recovery \\
\hline \multirow{2}{*}{ Tiannan lake } & \multirow{2}{*}{4.88} & 5 & 9.84 & $99.2 \%$ \\
\cline { 3 - 5 } & & 20 & 24.51 & $98.15 \%$ \\
\hline \multirow{2}{*}{ Tap water } & \multirow{2}{*}{1.49} & 5 & 6.46 & $99.4 \%$ \\
\cline { 3 - 5 } & & 20 & 21.58 & $100.45 \%$ \\
\hline
\end{tabular}

\section{Materials and Methods}

\subsection{Reagents and Materials}

All the starting materials were used without further purification. $\mathrm{AgNO}_{3}, \mathrm{HAuCl}_{4}, \mathrm{NH}_{3} \cdot \mathrm{H}_{2} \mathrm{O}$ were obtained from Sinopharm Chemical Regent Co. Ltd. (Shanghai, China). Tetraethyl orthosilicate (TEOS), 1-[3-(dimethylamino) propyl]-3-ethylcarbodiimide (EDC), 3-aminopropyl-trimethylsilane (APTES), and fluorescein isothiocyanate (FITC) were purchased from Aladdin Chemicals Co. Ltd (Shanghai, China). For all aqueous solutions, high-purity ultrapure water from a Millipore $(18.2 \mathrm{M} \Omega \cdot \mathrm{cm})$ system was used throughout the experiments.

\subsection{Measurements}

FRN were characterized by using high-resolution transmission electron microscopy (Hitachi, Japan). Ultraviolet-visible (UV-Vis) absorption spectra were acquired on a Cary 5000 spectrophotometer (Agilent, Palo Alto, CA, USA) coupled with a $1.00 \mathrm{~cm}$ quartz cell. All Fluorescence spectra were performed under $\lambda_{\mathrm{ex}}=380 \mathrm{~nm}$ with FluoroMax-4 (Horiba, Japan).

\subsection{Synthesis of FITC-SiO ${ }_{2}$ Microspheres}

The FITC $-\mathrm{SiO}_{2}$ microspheres was prepared according to a modified method that was previously reported [20], $1 \mathrm{mg}$ of FITC was weighed then dissolved in $5 \mathrm{~mL}$ of 1-hexanol, and $100 \mu \mathrm{L}$ of APTES was added in a small bottle. After that, the resulting mixture was stirred at medium speed for $12 \mathrm{~h}$ in the dark to obtain the FITC-APTES conjugate. Following this, $7.5 \mathrm{~mL}$ of cyclohexane, $1.4 \mathrm{~mL}$ of 1-hexanol, and $1.77 \mathrm{~mL}$ of TX-100 were added to a small bottle sequentially under low-speed stirring and stirred for $15 \mathrm{~min} ; 60 \mu \mathrm{L}$ of concentrated ammonia was added and stirred at medium speed for $15 \mathrm{~min} ; 400 \mu \mathrm{L}$ of FITC-APTES conjugate and $92 \mu \mathrm{L}$ of TEOS were added and stirred for $12 \mathrm{~h}$ in the dark; the product was centrifuged at $8000 \mathrm{rpm}$ for $8 \mathrm{~min}$ and washed twice with absolute ethanol to obtain FITC-SiO 2 microspheres.

\subsection{Synthesis of $A u N C s$}

AuNCs were prepared following previous method and minor modified [18]. $10 \mathrm{~mL}$ of $10 \mathrm{mmol} / \mathrm{L}$ aqueous $\mathrm{HAuCl}_{4}$ solution was added to $10 \mathrm{~mL}$ of $50 \mathrm{mg} / \mathrm{mL}$ BSA solution under vigorous stirring; $1 \mathrm{~mL}$ of $\mathrm{NaOH}$ solution $(1 \mathrm{~mol} / \mathrm{L})$ was then introduced to adjust $\mathrm{pH}$, and the mixture was incubated at $37^{\circ} \mathrm{C}$ for $12 \mathrm{H}$. The solution was then dialyzed in double distilled water for $48 \mathrm{H}$ to remove the unreacted $\mathrm{HAuCl}_{4}$ and $\mathrm{NaOH}$. The final solution was stored at $4{ }^{\circ} \mathrm{C}$ for further use.

\subsection{Synthesis of Amino-Modified FITC-SiO 2 Microspheres}

$1 \mathrm{~mL}$ of the above synthetic FITC- $\mathrm{SiO}_{2}, 6 \mathrm{~mL}$ of ethanol, $100 \mu \mathrm{L}$ of concentrated ammonia, and $15 \mu \mathrm{L}$ of TEOS and APTES were added to a small glass bottle, stirred for $2 \mathrm{~h}$, and washed twice with high purity water ( $8000 \mathrm{rpm}, 8 \mathrm{~min}$ ) to obtain amino-modified $\mathrm{FITC}-\mathrm{SiO}_{2}$ microspheres. 


\subsection{Synthesis of RFN}

Consequently, $20 \mathrm{mg}$ of EDC was weighed and dissolved in $1 \mathrm{~mL}$ of high-purity water, $4 \mathrm{~mL}$ of AuNCs was added, and the $\mathrm{pH}$ value of the reaction system was adjusted to 5.7 with $0.01 \mathrm{~mol} / \mathrm{L} \mathrm{HCl}$. After stirring for $30 \mathrm{~min}, 1 \mathrm{~mL}$ of $\mathrm{NH}_{2}-\mathrm{FITC}-\mathrm{SiO}_{2}$ was added to the system, the $\mathrm{pH}$ value of which was adjusted to 9.0 with $0.01 \mathrm{~mol} / \mathrm{L} \mathrm{NaOH}$. The reaction system was stirred for $12 \mathrm{~h}$ in the dark, then centrifuged twice with high-purity water to remove unreacted materials and collected with $1 \mathrm{~mL}$ of high-purity water to obtain RFN, as shown in Scheme 1.

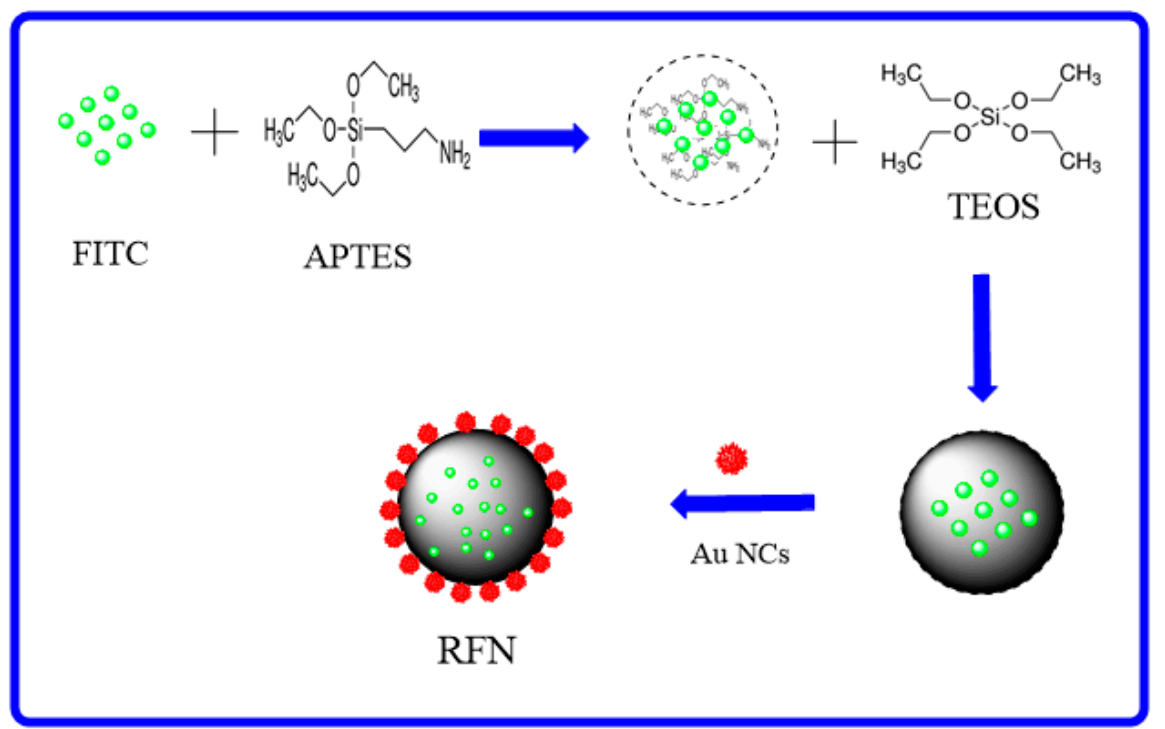

Scheme 1. Schematic illustration for preparation of the RFN.

\section{Conclusions}

In this study, the RFN was successfully synthesized and applied to the detection of mercury ions in water samples. The RFN had a simple synthesis procedure, high sensitivity, good stability, and strong anti-interference. The fluorescence intensity ratio of the RFN achieved the best effect at a $\mathrm{pH}$ value of 9.15. The RFN could detect $\mathrm{Hg}^{2+}$ in water simply and quickly, and the detection concentration ranged from $1.0 \times 10^{-10} \mathrm{~mol} / \mathrm{L}$ to $1.0 \times 10^{-8} \mathrm{~mol} / \mathrm{L}$, with the detection limit of $1.0 \times 10^{-10} \mathrm{~mol} / \mathrm{L}$. The advantages of good stability and high selectivity make the RFN suitable for monitoring heavy metal in waters. This method has a good application prospect for environmental protection.

Supplementary Materials: The Supplementary Materials are available online.

Author Contributions: Conceptualization, Z.L. and B.Z.; methodology, N.L. and G.H. formal analysis, L.C.; investigation, B.N.; data curation, Z.G. writing—original draft preparation, C.L.; writing—review and editing, H.X.

Funding: The authors gratefully acknowledge the support for this research by the Nature Science Foundation of China (21565028, 21765022), Guangxi Colleges and Universities Program of Innovative Research Team and Outstanding Talent, and the Key Project of Yulin Normal University (2015YJYB10).

Conflicts of Interest: The authors declare no conflict of interest.

\section{References}

1. Gustin, S.M.; Coolbaugh, M.; Engle, M.; Fitzgerald, B.; Keislar, R.; Lindberg, S.; Nacht, D.; Quashnick, J.; Rytuba, J.; Sladek, C.; et al. Atmospheric mercury emissions frommine wastes and surrounding geologically enriched terranes. Env. Geol. 2003, 43, 339-351. [CrossRef]

2. Clarkson, L.; Ma, T.W. Overview of the clinical toxicity of mercury. Ann Clin Biochem. 2006, 43, $257-268$.

3. Lippard, E.M.; Na, S.J. Tools and tactics for the optical detection of mercuric ion. Chem. Rev. 2008, 108, 3443-3480. 
4. Bansod, B.; Kumar, T.; Thakur, R.; Rana, S.; Singh, I. A review on various electrochemical techniques for heavy metal ions detection with different sensing platforms. Biosens. Bioelectro. 2017, 94, 443-455. [CrossRef] [PubMed]

5. Adlnasab, L.; Ebrahimzadeh, H.; Asgharinezhad, A.A.; Aghdam, M.N.; Dehghani, A.; Esmaeilpour, S. A Preconcentration Procedure for Determination of Ultra-Trace Mercury (II) in Environmental Samples Employing Continuous-Flow Cold Vapor Atomic Absorption Spectrometry. Food Anal. Meth. 2014, 7, 616-628. [CrossRef]

6. Noël, M.; Christensen, J.R.; Spence, J.; Robbins, C.T. Using laser ablation inductively coupled plasma mass spectrometry (LA-ICP-MS) to characterize copper, zinc and mercury along grizzly bear hair providing estimate of diet. Sci. Total. Env. 2015, 529, 1-9. [CrossRef] [PubMed]

7. Amiri, N.; Rofouei, M.K.; Ghasemi, J.B. Multivariate optimization, preconcentration and determination of mercury ions with (1-(p-acetyl phenyl)-3-(o-methyl benzoate)) triazene in aqueous samples using ICP-AES. Anal. Meth. 2016, 8, 1111-1119. [CrossRef]

8. Drummen, G. Fluorescent probes and fluorescence (microscopy) techniques-illuminating biological and biomedical research. Molecules 2012, 17, 14067-14090. [CrossRef] [PubMed]

9. Xu, S.; Zhou, K.; Fang, D.; Ma, L. Highly Sensitive and Selective Fluorescent Detection of Gossypol Based on BSA-Stabilized Copper Nanoclusters. Molecules 2019, 24, 95. [CrossRef] [PubMed]

10. Yang, Y.-K.; Yook, K.-J.; Tae, J. A Rhodamine-Based Fluorescent and Colorimetric Chemodosimeter for the Rapid Detection of $\mathrm{Hg}^{2+}$ Ions in Aqueous Media. J. Am. Chem. Soc. 2005, 127, 16760-16761. [CrossRef] [PubMed]

11. Cui, G.; Ye, Z.; Zhang, R.; Wang, G.; Yuan, J. Design and synthesis of a terbium (III) complex-based luminescence probe for time-gated luminescence detection of mercury (II) Ions. J. Fluoresc. 2012, 22, 261-267. [CrossRef] [PubMed]

12. Li, J.; Chen, J.; Chen, Y.; Li, Y.; Shahzad, S.A.; Wang, Y.; Yang, M.; Yu, C. Fluorescence turn-on detection of mercury ions based on the controlled adsorption of a perylene probe onto the gold nanoparticles. Analyst 2016, 141, 346-351. [CrossRef] [PubMed]

13. Freeman, R.; Finder, T.; Willner, I. Multiplexed Analysis of $\mathrm{Hg}^{2+}$ and $\mathrm{Ag}^{+}$Ions by Nucleic Acid Functionalized CdSe/ZnS Quantum Dots and Their Use for Logic Gate Operations. Angew. Chem. 2009, 121, 7958-7961. [CrossRef]

14. Joshi, B.P.; Park, J.; Lee, W.I.; Lee, K.-H. Ratiometric and turn-on monitoring for heavy and transition metal ions in aqueous solution with a fluorescent peptide sensor. Talanta 2009, 78, 903-909. [CrossRef] [PubMed]

15. Wang, Y.-Q.; Zhao, T.; He, X.-W.; Li, W.-Y.; Zhang, Y.-K. A novel core-satellite CdTe/Silica/Au NCs hybrid sphere as dual-emission ratiometric fluorescent probe for $\mathrm{Cu}^{2+}$. Biosen. Bioelectro. 2014, 51, 40-46. [CrossRef] [PubMed]

16. Liu, X.; Zhang, N.; Bing, T.; Shangguan, D. Carbon Dots Based Dual-Emission Silica Nanoparticles as a Ratiometric Nanosensor for $\mathrm{Cu}^{2+}$. Anal. Chem. 2014, 86, 2289-2296. [CrossRef] [PubMed]

17. Wang, J.; Jiang, C.; Wang, X.; Wang, L.; Chen, A.; Hu, J.; Luo, Z. Fabrication of an "ion-imprinting" dual-emission quantum dot nanohybrid for selective fluorescence turn-on and ratiometric detection of cadmium ions. Analyst 2016, 141, 5886-5892. [CrossRef] [PubMed]

18. Xie, J.; Zheng, Y.; Ying, J.Y. Highly selective and ultrasensitive detection of $\mathrm{Hg}^{2+}$ based on fluorescence quenching of $\mathrm{Au}$ nanoclusters by $\mathrm{Hg}^{2+}-\mathrm{Au}^{+}$interactions. Chem. Comm. 2010, 46, 961-963. [CrossRef] [PubMed]

19. Xie, J.; Zheng, Y.; Ying, J.Y. Protein-Directed Synthesis of Highly Fluorescent Gold Nanoclusters. J. Am. Chem. Soc. 2009, 131, 888-889. [CrossRef] [PubMed]

20. Ai, K.; Zhang, B.; Lu, L. Europium-Based Fluorescence Nanoparticle Sensor for Rapid and Ultrasensitive Detection of an Anthrax Biomarker. Angew. Chem. 2009, 121, 310-314. [CrossRef]

Sample Availability: Samples of the compounds are not available from the authors. 